\title{
The Incentive System of the Subject Librarians in the University Library
}

\author{
https://doi.org/10.3991/ijet.v16i03.20469 \\ Chunping Wang \\ Kunming University of Science and Technology, Kunming, China \\ Lili Song $(\bowtie)$ \\ Chongqing Three Gorges Vocational College, Chongqing, China \\ songlili20130yeah. net
}

\begin{abstract}
Based on the principal-agent theory, we introduce the specific task ability, construct the optimization model of the incentive system of the subject librarians, and discuss how to design the incentive system to achieve "win-win". According to the best incentive system, the variables are selected and measured by real data. An empirical model is established based on the econometrics theory, and the related theoretical conclusions are tested according to the empirical results. It is found that when the information is asymmetric, the best incentive system is composed of the optimal fixed income and the optimal value share. The higher the level of ability, managers should strengthen incentives and the subject librarians will increase the intensity of their efforts; the lower risk preference and the higher random selection, managers should weaken incentives and the subject librarians will reduce their efforts.
\end{abstract}

Keywords-Salary, incentive mechanism, principal agent

\section{Introduction}

The purpose of computer information retrieval teaching is to cultivate the information literacy of college students, which specifically includes: determining when they need information (information awareness); mastering the information source (information source); effectively obtaining the required information through a computer system (information acquisition ability); analyzing and evaluating the information and information sources, and integrating the selected information into its own knowledge base and value system (information evaluation); effectively organizing and managing the information, and effectively using it to complete specific tasks or solve problems (solve problems with information); combining the existing information to expand, reorganize or create new knowledge (information creation); confirming lifelong learning and access and use information under the premise of abiding by laws and ethics (information ethics). The core of information literacy is infor- 
mation awareness and the ability to obtain information. Solving problems with information retrieval is the ultimate goal of information literacy.

Computer information retrieval teaching is the core teaching task undertaken by subject librarians [1-4]. In addition, as the content of subject education services continues to expand, subject librarians also need to undertake the following four tasks

1. Provide scientific research guidance and literature information for different teachers

2. The construction of subject service platform, including computer website link service, computer system consulting service, computer resource recommendation, etc.

3. Recommendation of subject digital resources, allocate corresponding electronic digital collection resources for different subjects, and publicize various subject digital education resources through regular training lectures, etc.

4. Scientific research support services, including scientific and technological novelty search, paper retrieval, patent retrieval, information retrieval, etc.

In particular, the teaching of computer information retrieval not only requires subject librarians to have a solid foundation in information retrieval theory, but also requires subject librarians to be proficient in various comprehensive and professional computer retrieval systems. Database retrieval means that subject librarians retrieve documents related to scientific and technological innovation through a computer retrieval system.

With the rapid development of the computer Internet, the digital economy with data as a key production factor is becoming a new economic form, and "data" has become a major emerging production factor. The subject librarians of university library are proficient in using various computer data analysis tools, and can use these computer retrieval systems and analysis tools to carry out information retrieval, information analysis, data collation and so on, so as to provide accurate decision support and policy suggestions for the dynamic evaluation of disciplines, auxiliary decisionmaking, scientific research data support, teaching support and so on. Therefore, subject librarians have a pivotal relationship to the sustainable development of subject education in universities. How to build a scientific, reasonable, systematic and sustainable and effective subject librarian incentive management system is worthy of indepth analysis.

On the one hand, the survey of nearly 1000 subject librarians shows that the low salary level is the fundamental reason for lack of competitiveness, lack of ability, insufficient innovation, negative attitude, weak sense of responsibility, and serious brain drain of subject librarian. On the other hand, based on the existing literature, Silva and Tinuoye issued questionnaires and found that the compensation level has a significant impact on the job satisfaction of subject librarians, and more and more subject librarians are negotiating for higher salaries. Therefore, the compensation level is not only a unique incentive factor for subject librarians, but also the core and foundation for designing the incentive system.

Scholars at home and abroad have conducted extensive research on subject librarian compensation incentive mechanism and have achieved fruitful results. Wan implemented effective incentives for subject librarians through compensation incentives 
and other measures based on the perspective of psychological contract [5]. Yan proposed incentive mechanism guarantee measures for the subject service team from four aspects: compensation system, management philosophy, team culture, and evaluation system [6]. Wu conducted an in-depth analysis of the questionnaire data based on a questionnaire survey, and pointed out that the compensation level is an important factor for motivating subject librarians [7]. Hoodless believe that the position of subject librarians in subject services is irreplaceable, and functional experts cannot replace subject librarians [8-10]. Walters pointed out that most colleges and universities in the United States only give librarians the nominal status of teachers [11]. However, Mills and McCullough believe that granting teacher status does not improve the professional status of librarians, and suggest increasing the compensation of subject librarians through unionization and collective bargaining [12]. Silva conducted a survey of 846 subject librarians in ARL institutions and found that giving librarians a stable income is an important factor that motivates them to work harder [13]. Tinuoye conducted a descriptive survey design for 88 subject librarians in two universities in the United States, expounding the five factors that affect the job satisfaction of subject librarians: compensation level, working environment, fairness and justice, professional title and academic promotion and learning training, and found that the compensation level has a significant impact on the job satisfaction of subject librarians. Through effective incentives for five factors, it has a positive effect on the work efficiency of subject librarians and the provision of quality services to customers [14]. Silva and Galbraith found that compensation incentive is very important to subject librarians by issuing questionnaires to subject librarians who work in ARL Association. The longer the subject service-related work is, the higher the probability that subject librarians will negotiate for a higher salary, and the probability of women participating in salary negotiation is often lower than that of men [15].

In summary, scholars are mainly based on management perspectives or by issuing questionnaires, and proposing incentive measures through experience judgment and analysis, which lack solid theoretical support and data verification. Therefore, based on the principal-agent theory, this paper introduces the specific task ability, constructs the optimization model of subject librarian's compensation incentive system, designs the optimal salary incentive contract, analyzes the incentive characteristics, selects variables according to the salary incentive contract, measures the variables with real data, and establishes an empirical model based on the econometric theory for testing.

\section{Model}

\subsection{Model assumptions}

Hypothesis 1: The behavioural strategies of both the principal and the agent are to maximize their own interests, and the benefits of both parties are closely related to the effort level of the subject librarian. The subject librarians undertake two tasks and puts effort $\left(\mathrm{e}_{1}, \mathrm{e}_{2}\right)$ into it, where, $\left(\mathrm{e}_{1}, \mathrm{e}_{2}\right)$ represents the level of effort, and although the 
managers cannot fully observe the effort degree of the subject librarians, they can observe the result of their effort.

Hypothesis 2: Ability is the most important characteristic of subject librarians. Subject librarians have different abilities when they undertake different tasks, and ability has a significant impact on costs. Therefore, different task-specific ability variables are introduced. Set the effort cost function of the subject librarian as $C\left(e_{1}, e_{2}\right)=$ $\varphi_{1} e_{1}{ }^{2} / 2+\varphi_{2} e_{2}{ }^{2} / 2$, and the ability level of the subject librarian is reflected by the variable $\varphi \mathrm{i}$. That is, the stronger the ability, the smaller the variable $\varphi \mathrm{i}$, and vice versa, the lower the ability, the larger the variable $\varphi \mathrm{i}$, where the cost function $C\left(\mathrm{e}_{1}, \mathrm{e}_{2}\right)$ is a strictly increasing convex function, and $\mathrm{i}=1,2$.

Hypothesis 3: Set the service output of subject librarians as $S_{1}=e_{1}+\theta_{1}$ and $S_{2}=e_{2}+\theta_{2}$ respectively. This hypothesis shows that the service output of subject librarian is not only related to their own effort level, but also related to the randomness of the client's choice of subject services. $\theta_{1}$ and $\theta_{2}$ respectively represent the randomness of selecting discipline services, and obey a normal distribution with a mean of 0 and variances of $\sigma_{1}{ }^{2}$ and $\sigma_{2}{ }^{2}$ respectively. $\sigma_{1}{ }^{2}>0, \sigma_{2}{ }^{2}>0$ describe the degree of randomness of the client's selection of subject services.

Hypothesis 4: There is asymmetric information between managers and subject librarians, which means that managers cannot directly and clearly observe the effort level of subject librarians, but can only measure their service output. The manager supervises the behaviour selection of subject librarians and provides them with a linear compensation incentive contract $w=\alpha+b_{1} S_{1}+b_{2} S_{2}$ based on the service output, where $\alpha$ is the fixed income of the subject librarian, $b_{1}$ and $b_{2}$ respectively represent the share ratio obtained by the subject librarian, that is, the incentive intensity (incentive factor), and the incentive contract is complete.

Hypothesis 5: Assume that managers are risk-neutral and subject librarians are risk aversion, with an absolute risk aversion utility function $\mu=-e^{-\rho[w-C]}$, where $\rho=-$ $\mu^{\prime \prime} / \mu^{\prime}>0$ is the risk aversion coefficient, and the retention utility of subject librarians is $\bar{u}$.

\subsection{Model building}

Based on the above basic model assumptions, the total income obtained by the manager is the total output of the subject librarian, so the total income obtained by the manager is:

$$
S_{1}+S_{2}=e_{1}+\theta_{1}+e_{2}+\theta_{2}
$$

And then the expected total income of the manager can be obtained by:

$$
E\left(S_{1}+S_{2}\right)=E\left(e_{1}+\theta_{1}+e_{2}+\theta_{2}\right)=e_{1}+e_{2}
$$

The expected net income of the manager is the expected total income minus the cost to the subject librarian. Since managers are risk-neutral, it means that the ex- 
pected net utility is equal to their expected net benefits. Therefore, the manager's expected net utility is:

$$
\begin{aligned}
& E\left(S_{1}+S_{2}\right)-E(w) \\
& =E\left(e_{1}+\theta_{1}+e_{2}+\theta_{2}\right)-E\left(\alpha+b_{1} S_{1}+b_{2} S_{2}\right)=\left(1-b_{1}\right) e_{1}+\left(1-b_{2}\right) e_{2}-\alpha
\end{aligned}
$$

According to the above assumptions, subject librarians are risk averse and have a constant absolute degree of risk aversion. Therefore, the deterministic equivalent income of a subject librarian is equal to the expected return minus the risk cost it has paid. The expected return of a subject librarian is:

$$
E(w)=E\left(\alpha+b_{1} S_{1}+b_{2} S_{2}\right)=\alpha+b_{1} e_{1}+b_{2} e_{2}
$$

Then the certainty equivalent income (CE) of subject librarians can be obtained as:

$$
C E=\alpha+b_{1} e_{1}+b_{2} e_{2}-\frac{1}{2} \varphi_{1} \mathrm{e}_{1}^{2}-\frac{1}{2} \varphi_{2} \mathrm{e}_{2}^{2}-\frac{1}{2} \rho b_{1}^{2} \sigma_{1}^{2}-\frac{1}{2} \rho b_{2}^{2} \sigma_{2}^{2}
$$

Under the principal-agent relationship, the expected net income received by subject librarians should not be less than their retained income. When the expected net income is less than the retained income, the subject librarian refuses to accept the contract, and when the expected net income is greater than or equal to the retained income, the subject librarian accepts the contract. Therefore, the participation constraint of subject librarian (Individual Rationality, referred to as: IR) can be expressed as:

$$
\alpha+b_{1} e_{1}+b_{2} e_{2}-\frac{1}{2} \varphi_{1} e_{1}^{2}-\frac{1}{2} \varphi_{2} e_{2}^{2}-\frac{1}{2} \rho b_{1}^{2} \sigma_{1}^{2}-\frac{1}{2} \rho b_{2} \sigma_{2}^{2} \geq \bar{u}
$$

There is a conflict of interest between managers and subject librarians, subject librarians will only choose the level of effort that is conducive to maximizing their own interests, so a "moral hazard problem" arises. Therefore, the optimal incentive contract designed by the manager must maximize the interests of subject librarians while optimizing their own interests. Therefore, the Incentive Compatibility (IC) for subject librarians can be expressed as:

$$
\left(e_{1}, e_{2}\right) \in \arg \max _{e_{1}, e_{2}} \alpha+b_{1} e_{1}+b_{2} e_{2}-\frac{1}{2} \varphi_{1} e_{1}^{2}-\frac{1}{2} \varphi_{2} e_{2}^{2}-\frac{1}{2} \rho b_{1}^{2} \sigma_{1}^{2}-\frac{1}{2} \rho b_{2}{ }^{2} \sigma_{2}^{2}
$$

Therefore, under asymmetric information, the optimal incentive model of the subject service team can be expressed as: 


$$
\left\{\begin{array}{ccc}
\max _{\bar{\alpha}, \bar{b}_{1}, \bar{b}_{2}, \bar{e}_{1}, \bar{e}_{2}} & \left(1-b_{1}\right) e_{1}+\left(1-b_{2}\right) e_{2}-\alpha \\
\text { st. } & \text { (1) } & \alpha+b_{1} e_{1}+b_{2} e_{2}-\frac{1}{2} \varphi_{1} e_{1}^{2}-\frac{1}{2} \varphi_{2} e_{2}^{2}-\frac{1}{2} \rho b_{1}^{2} \sigma_{1}^{2}-\frac{1}{2} \rho b_{2}^{2} \sigma_{2}^{2} \geq \bar{u}(I R) \\
& \text { (2) } \quad\left(e_{1}, e_{2}\right) \in \arg \max _{e_{1}, e_{2}} \alpha+b_{1} e_{1}+b_{2} e_{2}-\frac{1}{2} \varphi_{1} e_{1}^{2}-\frac{1}{2} \varphi_{2} e_{2}^{2}-\frac{1}{2} \rho b_{1}^{2} \sigma_{1}^{2}-\frac{1}{2} \rho b_{2}^{2} \sigma_{2}^{2}(I C)
\end{array}\right.
$$

where, (1) is the participation constraint condition (Individual Rationality, referred to as IR) of subject librarian, (2) is the incentive compatibility constraint condition (Incentive Compatible, referred to as IC) of subject librarian.

\section{The Best Salary Incentive System and Incentive Characteristics}

By solving the above-mentioned incentive optimization model, we can obtain the optimal compensation incentive contract (b1, b2, e1, e2) for subject librarians under specific task ability. The specific solution results are shown in Table 1.

Table 1. The best incentive system

\begin{tabular}{|c|c|c|c|c|}
\hline $\begin{array}{l}\text { Incentive } \\
\text { variables }\end{array}$ & $\mathbf{e}_{1}$ & $\mathbf{e}_{2}$ & $\mathbf{b}_{1}$ & $\mathbf{b}_{2}$ \\
\hline & 1 & 1 & 1 & 1 \\
\hline & $\varphi_{1}$ & $\varphi_{2}$ & $\varphi_{1}$ & $\varphi_{2}$ \\
\hline & $\varphi_{1}\left(\frac{1}{\varphi_{1}}+\rho \sigma_{1}^{2}\right)$ & $\varphi_{2}\left(\frac{1}{\varphi_{2}}+\rho \sigma_{2}^{2}\right)$ & $\frac{1}{\varphi_{1}}+\rho \sigma_{1}^{2}$ & $\frac{1}{\varphi_{2}}+\rho \sigma_{2}^{2}$ \\
\hline
\end{tabular}

Table 1 shows the optimal compensation incentive system for subject librarians. Next, a comparative static analysis is made for the optimal compensation incentive system (b1, b2, e1, e2), and the derivation of the ability level $\varphi$, risk preference $\rho$ and external environmental uncertainty $\sigma 2$ are respectively obtained, and the specific derivation results are shown in Table 2. 
Table 2. Derivation results of the best incentive system

\begin{tabular}{|c|c|c|c|c|}
\hline Factors & $\mathrm{e}_{1}$ & $\mathbf{e}_{2}$ & $b_{1}$ & $\mathbf{b}_{2}$ \\
\hline$\varphi$ & $\frac{-\frac{1}{\varphi_{1}^{2}}-\frac{2 \rho \sigma_{1}^{2}}{\varphi_{1}}}{\left[1+\rho \sigma_{1}^{2} \varphi_{1}\right]^{2}}$ & $\frac{-\frac{1}{\varphi_{2}^{2}}-\frac{2 \rho \sigma_{2}^{2}}{\varphi_{2}}}{\left[1+\rho \sigma_{2}^{2} \varphi_{2}\right]^{2}}$ & $\frac{-\rho \sigma_{1}^{2}}{\varphi_{1}^{2}\left[\frac{1}{\varphi_{1}}+\rho \sigma_{1}^{2}\right]^{2}}$ & $\frac{-\rho \sigma_{2}^{2}}{\varphi_{2}^{2}\left[\frac{1}{\varphi_{2}}+\rho \sigma_{2}^{2}\right]^{2}}$ \\
\hline$\rho$ & $\frac{-\sigma_{1}^{2}}{\left[1+\rho \sigma_{1}^{2} \varphi_{1}\right]^{2}}$ & $\frac{-\sigma_{2}^{2}}{\left[1+\rho \sigma_{2}^{2} \varphi_{2}\right]^{2}}$ & $\frac{-\sigma_{1}^{2}}{\varphi_{1}\left[\frac{1}{\varphi_{1}}+\rho \sigma_{1}^{2}\right]^{2}}$ & $\frac{-\sigma_{2}^{2}}{\varphi_{2}\left[\frac{1}{\varphi_{2}}+\rho \sigma_{2}^{2}\right]^{2}}$ \\
\hline$\sigma^{2}$ & $\frac{-\rho}{\left[1+\rho \sigma_{1}^{2} \varphi_{1}\right]^{2}}$ & $\frac{-\rho}{\left[1+\rho \sigma_{2}^{2} \varphi_{2}\right]^{2}}$ & $\frac{-\rho}{\varphi_{1}\left[\frac{1}{\varphi_{1}}+\rho \sigma_{1}^{2}\right]^{2}}$ & $\frac{-\rho}{\varphi_{2}\left[\frac{1}{\varphi_{2}}+\rho \sigma_{2}^{2}\right]^{2}}$ \\
\hline
\end{tabular}

Based on Table 2, it can be concluded that with the change of subject librarian's the ability level $\varphi$, risk preference $\rho$ and randomness of subject service selection $\sigma 2$, the change trends of subject librarian's optimal effort level ei and optimal incentive system sharing proportion (optimal incentive intensity) bi are shown in Table 3.

Table 3. Change trends of factors

\begin{tabular}{|c|c|c|c|}
\hline Factors & $\boldsymbol{\uparrow}$ & $\boldsymbol{\rho} \uparrow$ & $\sigma^{2} \uparrow$ \\
\hline$e_{1}$ & $\downarrow$ & $\downarrow$ & $\downarrow$ \\
\hline$e_{2}$ & $\downarrow$ & $\downarrow$ & $\downarrow$ \\
\hline$b_{1}$ & $\downarrow$ & $\downarrow$ & $\downarrow$ \\
\hline$b_{2}$ & $\downarrow$ & $\downarrow$ & $\downarrow$ \\
\hline
\end{tabular}

\section{$4 \quad$ Empirical Study}

\subsection{The data}

The empirical research in this paper uses the new information retrieval institutions of university libraries under the Ministry of Education as samples. In view of the different approval years of each novelty search agency, the data of the sample from 2013 to 2015 were provided by the Science and Technology Development Centre of the Ministry of Education, and the data of other years were obtained by issuing questionnaires. Through sorting, inputting and analysing the massive data collected, the specific data features are as follows Table 4 and 5. 
Table 4. The descriptive statistics of variables

\begin{tabular}{|l|c|c|c|c|c|}
\hline Variables & Observed value & Mean value & Maximum value & Minimum value & Standard deviation \\
\hline $\operatorname{Ln}(\ln c)$ & 409 & 10.2854 & 12.2142 & 7.6824 & 0.6913 \\
\hline$A b i$ & 417 & 49.2771 & 196.4 & 2.1 & 33.0662 \\
\hline Ara & 316 & 0.0384 & 2.7603 & -0.7551 & 0.3828 \\
\hline Unc & 419 & 7.9116 & 15 & 1 & 5.2423 \\
\hline Lnfp & 411 & 6.9388 & 7.4955 & 6.2146 & 0.2645 \\
\hline Lndp & 411 & 6.3240 & 6.9077 & 5.7037 & 0.2528 \\
\hline Age & 419 & 9.6157 & 13 & 1 & 3.6605 \\
\hline
\end{tabular}

Table 5. The correlation analysis of variables

\begin{tabular}{|l|c|c|c|c|c|c|}
\hline \multicolumn{1}{|c|}{ Variables } & Abi & Ara & Unc & Lnfp & Lndp & Age \\
\hline Abi & 1.0000 & & & & & \\
\hline Ara & 0.2168 & 1.0000 & & & & \\
\hline Unc & 0.0494 & 0.0754 & 1.0000 & & & \\
\hline Lnfp & 0.0384 & -0.0510 & 0.3809 & 1.0000 & & \\
\hline Lndp & 0.0607 & -0.0348 & 0.3702 & 0.7405 & 1.0000 & \\
\hline Age & -0.0009 & -0.0673 & 0.0929 & -0.0182 & 0.0121 & 1.0000 \\
\hline
\end{tabular}

\subsection{The variables}

Explained variables: Incentive strength (value sharing ratio). Using the average annual incentive income obtained by subject librarians, the calculation formula is: average annual incentive income $=$ annual income of new information retrieval institutions in university libraries * incentive proportion / total number of subject librarians, where annual income $=$ domestic and foreign new search quantity $*$ domestic and foreign service price + domestic new search quantity $*$ domestic service price. The higher the incentive income, the greater the incentive intensity, which means the higher the proportion of service value shared by subject librarians.

Ability level: It is characterized by the ratio of the total annual service output of new information retrieval institutions of university libraries to the total number of subject librarians, that is, the average annual service output completed by subject librarians. The higher the quantity of service output, the higher the level of capability.

Risk preference: According to the practice of Faccio et al. [16-17], the risk preference is measured by the volatility of the profitability of the new information retrieval institutions of university libraries. And its calculation formula is: the ratio of this year's income to last year's income of University Library's novelty retrieval institutions minus 1.

Randomness of subject service selection: There is a certain degree of randomness for users to choose novelty search institutions in colleges and universities for services, which is measured by the ratio of the number of novelty search institutions in university libraries of each province (city) to the total number of novelty search institutions of the Ministry of Education. 
Control variables: The price of novelty search at home and abroad. This paper adopts the domestic and foreign price description stipulated by the University Library novelty retrieval institutions.

Domestic novelty search price: This paper adopts the domestic price description stipulated by the University Library novelty retrieval institutions.

Age of novelty search information retrieval institutions in university libraries: Since the approval period of the Ministry of Education ends in 2016, the difference between 2016 and the year when the information retrieval agency of university libraries was approved is used to describe its age.

The nature of University Library novelty search information retrieval institutions: To facilitate empirical research, the nature of university novelty search information retrieval institutions is divided into two types: science and engineering and nonscience and engineering (including comprehensive, agricultural, and medical), and 1 means science and engineering, 0 means non-science and engineering [18, 19].

\subsection{Empirical model}

Based on the theoretical analysis conclusions of the above-mentioned subject librarian's optimal compensation incentive management system, this paper constructs an empirical model composed of optimal incentive intensity, specific task capability, risk preference, and subject service selection randomness to verify the rationality of the theoretical model and the reliability of the theoretical conclusions.

In the equation for determining the optimal incentive intensity, taking specific task capabilities, risk preference, and subject service selection randomness as the core variables, the corresponding optimal incentive empirical model is constructed in turn as follows:

$$
\begin{aligned}
& \operatorname{Ln}\left(\ln c_{i t}\right)=\alpha+\beta_{1} A b i_{i t}+\beta_{2} A r a_{i t}+\beta_{3} U n c_{i t}+\varepsilon_{i t} \\
& \operatorname{Ln}\left(\ln c_{i t}\right)=\alpha+\beta_{1} A b i_{i t}+\beta_{2}\left(A r a_{i t}\right)^{2}+\beta_{3} A r a_{i t}+\beta_{4} U n c_{i t}+\varepsilon_{i t} \\
& \operatorname{Ln}\left(I n c_{i t}\right)=\alpha+\beta_{1} A b i_{i t}+\beta_{2}\left(A r a_{i t}\right)^{2}+\beta_{3} A r a_{i t}+\beta_{4} U n c_{i t} \\
& +\beta_{5} \operatorname{Ln}\left(f p_{i t}\right)+\beta_{6} \operatorname{Ln}\left(d p_{i t}\right)+\varepsilon_{i t} \\
& \operatorname{Ln}\left(\operatorname{Inc}_{i t}\right)=\alpha+\beta_{1} A b i_{i t}+\beta_{2}\left(A r a_{i t}\right)^{2}+\beta_{3} A r a_{i t}+\beta_{4} U n c_{i t}+\beta_{5} \operatorname{Ln}\left(f p_{i t}\right) \\
& +\beta_{6} \operatorname{Ln}\left(d p_{i t}\right)+\beta_{7} A g e_{i t} * \operatorname{Dum}_{i t}+\varepsilon_{i t} \\
& \operatorname{Ln}\left(I n c_{i t}\right)=\alpha+\beta_{1} A b i_{i t}+\beta_{2}\left(A r a_{i t}\right)^{2}+\beta_{3} A r a_{i t}+\beta_{4} U n c_{i t}+\beta_{5} \operatorname{Ln}\left(f p_{i t}\right) \\
& +\beta_{6} \operatorname{Ln}\left(d p_{i t}\right)+\beta_{7} A_{g e} * \operatorname{Dum}_{i t} * U n c_{i t}+\varepsilon_{i t}
\end{aligned}
$$

In the above-mentioned empirical model of optimal incentive intensity, $\alpha$ and $\beta$ are the parameters to be estimated respectively, $\mathrm{i}$ is the individual, $\mathrm{t}$ is the time, and $\varepsilon$ is the random disturbance term. $\operatorname{Ln}(\operatorname{lnc})$ represents the optimal incentive intensity, Abi- 
represents the ability level, Ara represents the risk preference of subject librarians, and Unc represents the randomness of subject service selection. Finally, the control variables that have a significant impact on service output are added to the above empirical model. The control variables mainly include: domestic and foreign prices Lnfp, domestic prices Lndp, age of information retrieval service agencies Age, nature of information service agencies Dum.

\subsection{Empirical result analysis}

Based on the empirical model of compensation incentives constructed step by step, through the measurement software Stata14.0, the regression results of the correlation between the optimal incentive intensity and the main core variables are shown in Table 6.

It can be seen from Table 6 that in each empirical model of incentive intensity, the specific task capability coefficient is positive and significant at the $1 \%$ level. It shows that the comprehensive ability of subject librarians has a higher impact on the intensity of incentives. The higher ability of subject librarians, the manager should strengthen incentives and increase the optimal sharing ratio of subject librarians to achieve the best expected income, which is consistent with the theoretical analysis conclusion Table 3. In model (1), the degree coefficient of subject librarian's risk preference is negative, indicating that the incentive intensity is negatively correlated with risk preference. Although it is consistent with the theoretical conclusion, it does not have a high impact on the incentive intensity. Considering that the quadratic term of risk preference is added into model (2), the first term and square term of risk preference are significant at the level of $10 \%$ and $1 \%$, respectively, which means that the square term of risk preference plays an important role in regulating its impact on incentive intensity, in addition, the relationship between incentive intensity and risk preference is not simple linear, but nonlinear. The random variables of subject service selection are positive and not significant in model (1) and model (2). And after adding the control variables domestic and foreign service prices Lnfp and domestic service prices Lndp to the model (3), the random variable of subject service selection turns from positive to negative and is significant at the $1 \%$ level. It shows that the greater the choice of the client for subject service, the manager should weaken the incentive to achieve the best self-interest, which is consistent with the theoretical conclusion. It means that the control variables play an important role in regulating the influence and correlation of randomness on the excitation intensity, and the control variables are all significant at the $1 \%$ level, which has a positive effect on the excitation intensity. Finally, in model (4) and model (5), the interaction terms of the control variables are added, namely the interaction term $A g e^{*}$ Dum between the age of the novelty retrieval institution and the nature of the novelty retrieval institution, and the interaction term Age*Dum*Unc among the age of the novelty retrieval institution, the nature of the novelty retrieval institution, and the randomness of the subject service selection. The interaction term is significant at the level of $5 \%$ and $1 \%$, and the coefficient of interaction term is positive, which means that the interaction term has a positive effect on the incentive intensity and has a higher impact on it. Moreover, the addition of control 
variables and interaction items will not affect the significance and relevance of the specific task ability level, risk preference, and randomness of subject service selection to the incentive intensity.

Table 6. The correlation regression analysis of the main variables

\begin{tabular}{|c|c|c|c|c|c|}
\hline Variables & Model 1 & Model2 & Model 3 & Model4 & Model 5 \\
\hline \multirow{2}{*}{$A b i$} & $0.0155^{\text {*** }}$ & $0.0151^{* * *}$ & $0.0152^{* * * k}$ & $0.0151^{* * * *}$ & $0.0151^{\text {*** }}$ \\
\hline & $(22.28)$ & (21.76) & $(27.21)$ & (27.43) & $(27.72)$ \\
\hline \multirow{2}{*}{ Ara } & -0.0200 & $0.0932^{*}$ & $0.1461^{* * *}$ & $0.1454^{* * *}$ & $0.1428^{* * * *}$ \\
\hline & $(-0.47)$ & $(1.74)$ & $(3.08)$ & $(3.08)$ & $(3.03)$ \\
\hline \multirow{2}{*}{$A r a^{2}$} & & $-0.1298^{* * *}$ & $-0.1537^{* * *}$ & $-0.1529^{* * *}$ & $-0.1494^{* * *}$ \\
\hline & & $(-3.33)$ & $(-4.38)$ & $(-4.37)$ & $(-4.28)$ \\
\hline \multirow{2}{*}{ Unc } & 0.0086 & 0.0094 & $-0.0132^{* * * *}$ & $-0.0144^{* * * *}$ & $-0.0224^{* * * *}$ \\
\hline & $(1.30)$ & $(1.43)$ & $(-2.93)$ & $(-3.22)$ & $(-4.27)$ \\
\hline \multirow{2}{*}{ Lnfp } & & & $0.4150^{* * *}$ & $0.3681^{* * *}$ & $0.3585^{* * *}$ \\
\hline & & & $(3.75)$ & $(3.31)$ & $(3.29)$ \\
\hline \multirow{2}{*}{ Lndp } & & & $0.6936^{* * *}$ & $0.7425^{* * *}$ & $0.7561^{* * * *}$ \\
\hline & & & $(5.97)$ & $(6.36)$ & $(6.59)$ \\
\hline \multirow[t]{2}{*}{ Age $*$ Dum } & & & & $0.0091^{* *}$ & \\
\hline & & & & (2.29) & \\
\hline \multirow{2}{*}{ Age ${ }^{*}$ Dum $^{*}$ Unc } & & & & & $0.0013^{* * * *}$ \\
\hline & & & & & $(3.12)$ \\
\hline Within $^{2}$ & 0.5835 & 0.6009 & 0.6656 & 0.6663 & 0.6666 \\
\hline Between $^{2}$ & 0.7230 & 0.7281 & 0.8891 & 0.8936 & 0.8992 \\
\hline Overall $^{2}$ & 0.7042 & 0.7113 & 0.8462 & 0.8523 & 0.8534 \\
\hline$N$ & 315 & 315 & 315 & 315 & 315 \\
\hline
\end{tabular}

Note: $* * *, * *, *$ indicate that the correlation coefficient is significant at the level of $1 \%, 5 \%$, and $10 \%$, respectively.

\section{Conclusion}

We construct the optimal incentive system model under the specific task ability of the subject librarians. The best incentive system is designed, the incentive characteristics are analysed, and the empirical model is established to test relevant theoretical conclusions. We show that the optimal compensation incentive system is composed of the optimal fixed income and the optimal value share of subject service. The higher share ratio obtained by subject librarians, the higher their level of effort. The lower the risk preference, and the higher random selection, managers should weaken incentives. Moreover, the higher ability, managers should strengthen incentives and subject librarians will increase the intensity of their efforts. 


\section{Acknowledgement}

This work was supported in part by Talent Training Project of Kunming University of Science and Technology (Grant No. KKSY201814014), Planning Project of Yunnan Provincial Philosophy and Social Sciences (Grant No. QN2018046).

\section{$7 \quad$ References}

[1] Pang, L. (2020). Teaching mode of library information literacy course based on hierarchical embedded service, International Journal of Emerging Technologies in Learning, 15(10): 27-41. https://doi.org/10.3991/ijet.v15i10.13995

[2] Mukminatien, N., Yaniafari, R.P., Kurniawan, T., Wiradimadja, A. (2020). CLIL audio materials: A speaking model for library science department students, International Journal of Emerging Technologies in Learning, 15(7): 29-42. https://doi.org/10.3991/IJET.V15 $\underline{\mathrm{I} 07.13223}$

[3] Xiao, Q. (2020). Resource classification and knowledge aggregation of library and information based on data mining. Ingénierie des Systèmes d'Information, 25(5): 645-653. https ://doi.org/10.18280/isi.250512

[4] Barbini, A., Malacarne, G., Romagnoli, K., Massari, G.A., Matt, D.T. (2020). Integration of life cycle data in a BIM object library to support green and digital public procurements. International Journal of Sustainable Development and Planning, 15(7): 983-990. https ://doi.org/10.18280/ijsdp.150702

[5] Wan, W.J. (2017). Research on the motivation of library subject librarians from the perspective of psychological contract. Research in Library Science, (20), 97-101.

[6] Yan, Q.J. (2017). Research on incentives of subject service teams in university libraries based on comprehensive incentive theory. Journal of Agricultural Library and Information Science, 29(12), 212-214.https://doi.org/10.13998/j.cnki.issn1002-1248.2017.12.048

[7] Wu, H.W. (2014). An empirical analysis of motivation factors for subject librarians. Journal of Agricultural Library and Information Science, 26(4), 193-196.

[8] Wang, M.Q., Li, Y.J. (2016). A two-stage DEA model for supplier evaluation with dual roles and undesirable elements. Chinese Management Science, 24(12), 91-97. https://doi. org/10.16381/j.cnki.issn1003-207x.2016.12.011

[9] Geng, X.L., Ye, C.M. (2014). Service supplier evaluation method based on intuitionistic fuzzy VIKOR. Industrial Engineering and Management, 219(3), 18-25. https://doi.org/10. 3969/j.issn.1007-5429.2014.03.004

[10] Hoodless, C., Pinfield, S. (2018). Subject vs. functional: Should subject librarians be replaced by functional specialists in academic libraries? Journal of Librarianship and Information Science, 50(4), 345-360.https://doi.org/10.1177\%2F0961000616653647

[11] Walters, W.H. (2016). Faculty status of librarians at US research universities. The Journal of Academic Librarianship, 42(2), 161-171.https://doi.org/10.1016/j.acalib.2015.11.002

[12] Mills, C., McCullough, I. (2018). Academic librarians and labor unions: Attitudes and experiences. portal: Libraries and the Academy, 18(4), 805-829. https://doi.org/10.1353/ pla.2018.0046

[13] Silva, E., Galbraith, Q., Groesbeck, M. (2017). Academic librarians' changing perceptions of faculty status and tenure. College \& Research Libraries, 78(4), 428. https://doi.org/10. $\underline{5860 / \mathrm{crl} .78 .4 .428}$ 
[14] OyovweTinuoye, G.O., Omeluzor, S.U., Akpojotor, L.O. (2016). Factors influencing job satisfaction of academic librarians in university libraries in Edo and Delta states, Nigeria. The Electronic Library, 34(6), 985-996. https://doi.org/10.1108/EL-07-2015-0128

[15] Silva, E., Galbraith, Q. (2018). Salary negotiation patterns between women and men in academic libraries. College \& research libraries, 79(3), 324. https://doi.org/10.5860/crl.79. $\underline{3.324}$

[16] Faccio, M., Marchica, M.T., Mura, R. (2011). Large shareholder diversification and corporate risk-taking. The Review of Financial Studies, 24(11), 3601-3641. https://doi.org/ $\underline{10.1093 / \mathrm{rfs} / \mathrm{hhr} 065}$

[17] Faccio, M., Marchica, M. T., Mura, R. (2016). CEO gender, corporate risk-taking, and the efficiency of capital allocation. Journal of corporate finance, 39, 193-209. https://doi.org/ 10.1016/j.jcorpfin.2016.02.008

[18] Holmstrom, B., Milgrom, P. (1991). Multi-task principal-agent problems: Incentive contracts, asset ownership, and job design. Journal of Law, Economics and Organization, 7, 24-52. https://doi.org/10.1093/jleo/7.special_issue.24

[19] Holmstrom, B., Milgrom, P. (1987). Aggregation and linearity in the provision of intertemporal incentives. Journal of the Econometric Society, 55(2),303-328. https://doi. org/10.2307/1913238

\section{Authors}

Chunping Wang is a member of Library, Kunming University of Science and Technology, Kunming 650500, China. Her research interests include computer information retrieval and principal-agent. Email: wcptsg@126.com

Lili Song is a member of School of Economics and Management, Chongqing Three Gorges Vocational College, Chongqing 404155, China. Her research interests include human resource management and marketing. Email: songlili2013@yeah.net

Article submitted 2020-12-08. Resubmitted 2021-02-02. Final acceptance 2021-02-06. Final version published as submitted by the authors. 